\title{
WHY DO WE NEED A PACIFIC REGIONAL HUMAN RIGHTS COMMISSION?
}

\author{
P Imrana Jalal *
}

This article discusses the need for a Pacific regional human rights mechanism. The author favours a regional human rights commission established by a Pacific human rights charter. The article canvasses previous attempts to set up a regional mechanism and explains why these initiatives failed. Advantages of a regional mechanism are explained, with an emphasis on the Pacific region's need for a common initiative. Finally, practical challenges and strategies involved in implementing a regional human rights mechanism are explored.

\section{INTRODUCTION}

Samoa was the first Pacific Island Country and Territory (PICT) to have ratified the United Nations Convention on the Elimination of Discrimination Against Women (CEDAW) ${ }^{1}$ and to have acceded to the International Covenant on Civil and Political Rights (ICCPR). ${ }^{2}$ Samoa was also one of the first countries to apply human rights standards from the Conventions in the courts, notwithstanding non-ratification of that Convention. ${ }^{3}$ In November 2007, Samoa also passed legislation implementing the Rome Statute of the International Criminal Court. ${ }^{4}$

* Human Rights Adviser at the Pacific Regional Rights Resource Team. With support from RRRT Senior Legal and Human Rights Trainer Teaiaki Koae. The final post-conference paper takes into account comments made at the Conference as a result of my paper and my responses to those comments. I have made reference to this whenever I have chosen to include these comments.

1 Convention on the Elimination of all Forms of Discrimination Against Women (18 December 1979) 1249 UNTS 13 [CEDAW] ratified by Samoa on 25 September 1992.

2 International Covenant on Civil and Political Rights (16 December 1966) 999 UNTS 171 [ICCPR], acceded to by Samoa on 15 February 2008.

3 P I Jalal and J Madraiwiwi (eds) (2005) 1 Pacific Human Rights Law Digest.

4 International Criminal Court Act 2007, Art 7 www.parliament.gov.ws/legislations.cfm, and the Criminal Procedure Act 1972, Art 112 www.parliament.gov.ws/legislations.cfm. 
It is the hallmark of the Samoan nation, unlike some others in the region, that it lays great faith in the rule of law and democracy, that it solves its problems in the courts of law, not on the streets of Apia, and not because of the looming presence of the gun. Samoa, although far from perfect, is a bastion of stability in a region becoming more recognised for its problems of governance and instability than its beautiful beaches and warm, smiling people.

It should also be noted that Tonga and Vanuatu recently signed the Convention on the Rights of Persons With Disabilities (CRPLD) ${ }^{5}$ and Vanuatu the ICCPR. ${ }^{6}$ Congratulations to those ex-USP Law School PDLP students who have done human rights courses from Samoa, Vanuatu and Tonga for playing such important roles in these processes.

I have been asked to discuss the need for a Pacific regional human rights mechanism. Let me declare at the beginning that I regard that appropriate mechanism to be a human rights commission. The establishment of a regional commission often presupposes the existence of a Pacific Charter of Human Rights establishing such a commission, so a charter might be the first step. Agreeing on a charter and commission will both be a long process. The ultimate form of a Pacific regional mechanism will depend on what type of commission PICTs want.

Throughout my working life I have been involved with human rights issues, either as an advocate lobbying for changes to laws in my home country, Fiji, or by providing policy advice or training to Pacific government agencies or to non-government organisations (NGOs) and partners on broad human rights issues and policy matters.

Our organisation, the Pacific Regional Rights Resource Team (RRRT), has also played an active role through our regional programmes with Members of Parliament (MPs), judicial officers, policymakers and our partner organisations in Pacific Island countries in getting Governments to consider adopting human rights compliant policies and practices. We have also provided advice and assistance on ratification of a number of international human rights conventions as well as in the compilation of the requisite reports that come with ratification.

My primary focus is on PICTs that are members of the Pacific Islands Forum (PIF), and/or the Secretariat of the South Pacific Community (SPC). ${ }^{7}$ Australia and New Zealand each have well functioning institutions and for practical purposes should not be included in the initial regional mechanism although options for them to join later should be made available, and welcomed. I do

5 Convention on the Rights of Persons With Disabilities (13 December 2006) UN Doc A/61/611, signed by Vanuatu on 17 May 2007 and by Tonga on 23 September 2007.

6 ICCPR, above n 2, was ratified by Vanuatu on 21 November 2008.

7 These are: American Samoa, Cook Islands, Federated States of Micronesia, Fiji Islands, French Polynesia, Guam, Kiribati, Marshall Islands, Nauru, New Caledonia, Niue, Northern Mariana Islands, Palau, Papua New Guinea, Pitcairn Islands, Samoa, Solomon Islands, Tokelau, Tonga, Tuvalu, Vanuatu, Wallis and Futuna. 
not think it desirable that discussion and debate within both countries, which no doubt will be complex and protracted, should halt the momentum that might arise out of this symposium.

The preparation of a Pacific Charter of Human Rights and regional commission does not necessarily require the ratification of all PICTs to bring it into existence, although the process of drafting should hopefully involve all. It might well be the case that some countries might ratify immediately and others later when they are ready. We ought, notwithstanding, to surge ahead and those countries that are interested should join the process, whilst others may join in their own good time.

\section{WHY A HUMAN RIGHTS COMMISSION AT ALL?}

Before we look at whether or not we need a regional mechanism to protect, respect and promote human rights in the region, we need to discuss first the advantages of having a human rights commission of any sort, whether national or regional. As many of our countries have basic bills of rights which protect mainly civil and political rights (and some protect a very few economic, social and cultural rights) in our Pacific constitutions, and given that virtually all our countries have signed up to at least one United Nations human rights convention, I do not intend to elaborate here on the persuasive argument for human rights in the Pacific.

However, I will look briefly at the overall advantages of having human rights commissions before looking at why we need a regional one. They may be briefly listed as follows:

(1) The framework for the protection of human rights is granted in bills of rights in our own constitutions, as well as in ratified human rights conventions, but their realisation is illusory without specialised protection available to ordinary Pacific islanders;

(2) It provides a dedicated institution to promote, protect, respect and defend human rights in a non-adversarial process using mediation and conciliation (generally using the courts as a last resort). The majority of disputes can be conciliated through alternative dispute resolution without expensive litigation. This process is also culturally more appropriate for the Pacific than the adversarial process;

(3) It is a cheaper alternative to the courts for citizens and more accessible to the public. Courts are expensive and only really available to those who can afford lawyers;

(4) The state can be seen to be supportive of its citizens' human rights promoting good public relations to the world;

(5) A commission can be resourced by specialists, commissioners and other staff (whereas most PICTs cannot afford specialised courts);

(6) Commissions can provide guidance to Governments on compliance; 
(8) It can take responsibility for writing reports for the UN human rights treaty bodies and for appearing before these bodies and reporting on behalf of Governments (PICTs find the reporting process burdensome from a human and financial resource perspective);

(9) It can be a useful conduit for access to the Office of the High Commissioner for Human Rights (OHCHR), for its technical support and aid;

(10) For judges, magistrates, lawyers and NGOs, a commission is a useful and free resource for cases and precedents and the sharing of appropriate standards. Despite recent events, which have allegedly seriously undermined the independence and credibility of the Fiji Human Rights Commission, it did some sterling work in this area arguing landmark discrimination cases. I was one of the first two appointed Human Rights Commissioners in 1998 and helped set up the Commission. It would be extremely unfair to judge the work of the Commission based on the alleged actions of a few. Commissioner Shamima Ali is a fine example of a Commissioner of the FHRC who has done everything absolutely correctly, and within the rule of law;

(11) It is a useful forum to facilitate dissemination of rights knowledge and skills in the Pacific and facilitate NGO participation in governance; and

(12) It can be an independent/mediatory body between governments and the NGO/CSO sector.

This list is far from exhaustive. In summary, it is politically strategic, legally feasible and in the long run, just makes plain economic sense, for Governments to establish national human rights institutions (NHRIs) and/or a regional mechanism.

\section{PREVIOUS INITIATIVES TO SET UP A REGIONAL MECHANISM}

The proposal to set up a human rights mechanism for PICTs has been around for more than twenty years. ${ }^{8}$ The first attempt was made in 1982 when the UN sponsored a seminar on National, Local and Regional Arrangements for the Promotion and Protection of Human Rights in the Asia Pacific Region in Colombo. The seminar was followed by a series of annual workshops, also hosted by the UN, involving government representatives from the region. From the first workshop held in Manila in 1990 to the Beijing workshop in 2005, thirteen such annual workshops were held. ${ }^{9}$

In 1985, an NGO called the Law Association for Asia and the South Pacific (LAWASIA) started exploring the possibility of a regional mechanism for the Pacific at a meeting in Fiji. I attended that meeting held at Pacific Harbour, as a member of the Fiji Attorney-General's Office and

8 This history is documented in V Muntarbhorn "In Search of the Rights Track: Evolving a Regional Framework for the Promotion and Protection of Human Rights in the Asia-Pacific Region" Discussion Paper (OHCHR, June 2005).

9 Ibid. For a description of some of these workshops, see Sou Chiam "Asia's Experience in the Quest for a Regional Human Rights Mechanism" in this volume. 
followed events related to it after that. The meeting was attended by 63 governmental and NGO delegates but was overwhelmingly dominated by Asian, Australian and New Zealand representatives.

After various working party meetings, a draft Pacific Charter of Human Rights was adopted at a meeting held in Samoa in 1989. The draft was modelled closely on the African Charter on Human and Peoples' Rights ${ }^{10}$ and provided for civil and political rights, and some economic, social and cultural rights. It foresaw the establishment of a commission to supervise implementation.

As with some initiatives, LAWASIA efforts failed to gain support from PICT Governments. One commentator stated the reasons for the failure of such initiatives as being: ${ }^{11}$

(1) Lack of follow-up and evaluation;

(2) Inadequate space for participation from stakeholders other than the governments;

(3) At times those participating at the government level were not of high enough rank to have real impact;

(4) Some of the relevant agencies and personnel had not been brought onboard; and

(5) Lack of a regional commitment by governments.

To these reasons, I would add more compelling political and social ones rooted in local realities:

(1) The irrelevance of what was perceived as "Western" human rights values and the perceived clash with Pacific values;

(2) There was little recognition of the value of ratifying international human rights treaties in the mid-1980s and hardly any of the core human rights treaties were ratified;

(3) The absence of a mandate for any particular regional organisation at the time to oversee the establishment of a regional mechanism envisaged by LAWASIA. ${ }^{12}$ Most importantly the initiative was perceived to be driven by outsiders and not Pacific islanders (to many it still seems so) - this is a salutary warning to all of us, that if this initiative is seen to be driven by outsiders, no matter how well intentioned or sensitive to Pacific Islanders and their concerns, the initiative will fail. The important lesson for all is that outside expertise, human and financial resources are needed but PICTs must lead the initiative;

10 African Charter of Human Rights (27 June 1981) 1520 UNTS 217.

11 Muntarbhorn, above n 8, 9.

12 For example, regional organisations such as the PIF or the Secretariat of the Pacific Community were not tasked with the necessary follow up. 
(4) A key reason also was that the NGOs had not been included nor brought on board. Without civil society ownership the idea was doomed to failure from the beginning. Even though NGOs were at the meeting at Pacific Harbour, by and large they were not skilled at negotiation as they are now, they knew very little about human rights and in any case they were given little political space to make any meaningful input; and

(5) The initiatives suffered from simple bad timing, tied in with a lack of local Pacific ownership of the concept - how could a region, at that stage not knowledgeable about human rights but also seemingly hostile to human rights for a variety of cultural or other reasons go as far as considering a regional human rights commission? PICTs could not see the value of a regional charter of human rights nor a regional commission. We appear to have passed beyond this stage.

Timing is critical. In stark contrast this time, in 2007 and 2008, Pacific island MPs, judicial officers and NGOs have called for the setting up a regional mechanism, ${ }^{13}$ echoing goals in the Pacific Plan. ${ }^{14}$

A renewed call for a Pacific regional mechanism is now being made under Strategic Objectives 12.1 and 12.5 of the Pacific Plan. The Secretary General of the Pacific Islands Forum has said that what was needed to implement certain strategic objectives in the Pacific Plan was: ${ }^{15}$

Support for the regional consolidation of commitments to key institutions such as audit and ombudsman offices, leadership codes, anti-corruption institutions and departments of attorneys general, including through judicial training and education. This set of objectives includes the establishment of a regional ombudsman and other human rights mechanisms to support the implementation of the Forum's accountability and leadership principles, a regional audit service to support integrity and oversight and a regional anti-corruption agency with associated legislation.

Thus, unlike the 1980s when the call was identified more with interest and persons considered to be "outsiders" to the Pacific region, the call this time has been made by people and institutions from within the Pacific. The prevailing conditions in the region have changed, and the time is now right

13 Pacific Regional Consultation for Members of Parliament on the Pacific Plan (Strategic Objective 12.5), Human Rights Conventions \& Standards and their Application to Domestic Law Policy and Practice (29 October-2 November 2007); Regional Consultation for Judges and Magistrates on Human Rights Conventions and Standards and their Application to Domestic Law, Policy and Practice (3-7 December 2007); RRRT Regional Partner NGOs Meeting (14-15 February 2008).

14 Recommended in the Pacific Regional Consultation for Members of Parliament on the Pacific Plan, above n 13, Strategic Objectives 12.1 and 12.5.

15 PIF Secretariat Secretary General Greg Urwin "Keynote Address" (Inaugural Pacific Network Meeting, Sigatoka, Fiji, 12 December 2007). 
to revive discussion and action on the long-standing need for a regional human rights commission for the Pacific region. Some of these conditions are:

(1) Better understanding of human rights by Pacific peoples and PICT Governments. Although human rights knowledge is limited it is still significantly greater than in 1985;

(2) The existence of organisations specifically dedicated to human rights dissemination, and or activism, and a larger number of NGOs who value and promote human rights through their own sectoral interests (the growing appreciation of rights based approaches);

(3) Greater number of ratification of human rights treaties/conventions and reporting under the treaties;

(4) Greater use of human rights standards by the courts;

(5) Greater use of the language of human rights by politicians and PICT Governments;

(6) In 1985-1989 there was no in-house Pacific island expertise; almost all the region's human rights expertise was based in Australia and New Zealand. That is no longer the case. There are organisations (especially NGOs) and individuals who have a critical mass of human rights knowledge which is growing day by day; and

(7) In the 14 years that RRRT has been working in the Pacific there has been a gradual thawing of hostility towards the notion of human rights, and a gradually growing appreciation of it. One of the reasons for this is that human rights are being taught, disseminated, used and acted on by Pacific islanders themselves. It is much more difficult for those Pacific Islanders resisting human rights to accuse other Pacific islanders who promote human rights that they are "western values being shoved down our throats." The old adage, that the messenger is as important as the message, is never truer than in the promotion of human rights in this region.

The list is not exhaustive but more than 23 years have passed and much has changed in the Pacific since 1985. To use the somewhat overused cliché, establishing a regional human rights charter and commission is an idea whose time has come.

\section{WHY DO WE NEED A REGIONAL HUMAN RIGHTS COMMISSION IN THE PACIFIC?}

The establishment of a regional commission does not preclude the establishment of a national commission for those countries able to achieve this. The argument for a regional commission is not an either/or situation or a national versus regional one. Both are desirable. However for many PICTs this may be very difficult. A further caveat is that a regional commission suggests the existence of a regional human rights charter endorsed by PICTs. In 1985 and thereafter, PICT Governments were promoting the concept of a Pacific charter with "Pacific values" (similar to the so called "Asian 
values" notion) a clear signal at that time that it would be difficult to agree on a charter embodying universal standards.

A regional charter ought not to derogate from or be looser than international standards, nor condone any notion of cultural relativism. Cultural sensitivity is different from cultural relativism, the former being an acknowledgement that Pacific island cultures are like all cultures, idiosyncratic. Sensitivity in approach and form is critical. However, Pacific peoples and Pacific culture are not so different that international human rights standards and norms ought not to apply. We are not lesser people entitled to lesser rights. Nor, if it is applicable, should we derogate from our own standards if anything we should be levelling up, not down, from our own Pacific island conditions.

The charter should reinforce the universal rights established by international human rights instruments but should also be expanded to recognise rights and duties that are particular to PICTs. In giving recognition to these rights and duties, care should be taken to ensure that they do not conflict with or whittle down universal rights. Some rights which may be considered peculiar to the Pacific (although perhaps not exclusively) are:

(1) The right to fish as an essential component of food security (fish is the only real source of protein for most Pacific Islanders). In Fiji fishing rights are known as qoliqoli rights; and

(2) The right to a safe or quality environment or land to live on (the right to land and adequate housing/shelter) has taken on new dimensions in the Pacific. I accept that climate change may be devastating to all humanity globally but the reality is that its effects are being felt disproportionately in the Pacific islands, especially in low-lying atolls. Under this right, issues such as coral bleaching and marine life, and the economic losses related to tourism might be accommodated. Indeed it has been suggested that a regional charter might well include such a specific right that has not gained momentum globally. ${ }^{16}$ I would go one step further and say that this right, of such great importance to PICT Governments, might well be the hook upon which we could hang a regional charter of human rights.

Cultural rights are already a universal standard recognised in the International Covenant on Economic, Social and Cultural Rights. ${ }^{17}$ However they may not be used, for example, to undermine rights to equality for women. How a Pacific Charter of Human Rights and a Pacific Regional Human Rights Commission might add value however, is in bringing the realisation of universal standards closer to home. There are several reasons why a Pacific Regional Human Rights Commission is necessary for the Pacific. These will be discussed below.

16 Justice Susan Glazebrook "Human Rights and the Environment" in this volume.

17 International Covenant on Economic, Social and Cultural Rights (16 December 1966) 993 UNTS 3. 


\section{A A Regional Mechanism Takes Better Account of Regional Conditions and Peculiarities}

The UN encourages the establishment of regional human rights mechanisms because the experience from other regions with such mechanisms is that they are able to take better account of regional conditions and peculiarities. ${ }^{18}$ For the Pacific such peculiarities might include the duty of individuals to their family and community - an area of concern given the often expressed view in the Pacific that human rights favour the rights of individuals over the rights of the community.

In essence, a regional human rights commission will not only complement the UN system at a regional level, but it will be more acceptable to Pacific people and have a greater capacity to promote human rights values because:

(1) There will be more state commitment to it given the involvement of PICT Government leaders in its formulation, inception and governance;

(2) It will instill a sense of ownership in people not only because their Governments or organisations were involved in formulating it but also because it is more visible and accessible to them - the location of most offices of the UN in Europe have made it very difficult for Pacific people to identify with them. Even some UN offices located in the Pacific are regarded as inaccessible;

(3) It will be staffed by the "sons and daughters of the region", so the acceptance of human rights standards by people and organisations in the region may be easier to obtain;

(4) The perception that human rights are Western concepts and therefore have no relevance to PICTs will be better addressed;

(5) It will provide an avenue for regional dialogue and the means to resolve regional human rights disputes; and

(6) It will assist in the implementation of the Pacific Plan, UN human rights treaty commitments and other regional agreements.

The Pacific Plan, adopted by PIF leaders in 2005, envisaged a region that is "respected for the quality of its governance, the sustainable management of its resources, the full observation of democratic values, and for its defence and promotion of human rights". ${ }^{19}$ The Pacific Plan was

18 From 1986-1990 the UN General Assembly passed three such resolutions. For example, Resolution 41/153 passed in 1986 and titled "Regional Arrangements for the Promotion and Protection of Human Rights in the Asian and Pacific Region" called upon states from the region to respond to the call for "regional arrangements". The UN Human Rights Council (previously Commission) had also made nine similar calls. See Muntarbhorn, above n 8.

19 PIF Secretariat "The Pacific Plan For Strengthening Regional Co-operation and Integration" (2006) 2 www.forumsec.org/pages.cf./documents/pacificplan/final-2005.html (accessed 15 February 2008) (emphasis added). 
launched in 2006; under its Good Governance Objective 12.1, one milestone identified for implementation in 2006-2008 is the establishment of a regional ombudsman and other human rights mechanisms to support the realisation of PIF's Principles of Good Leadership and Accountability. ${ }^{20}$ Never before has such a clear mandate for a regional human rights mechanism been so pronounced by Pacific Leaders.

In the Pacific Plan, Pacific Leaders called for immediate implementation by its member countries: "where appropriate, [the] ratification and implementation of international and regional human rights conventions, covenants and agreements and support for reporting and other requirements". ${ }^{21}$ The inclusion of regional human rights conventions in this objective is noteworthy. At present, no such regional human rights convention is in existence for the Pacific region. If anything, the specific reference to a regional human rights convention is by itself a call for one to be formulated for the region. A Pacific Charter of Human Rights and a commission might well be that regional convention. The mandate by PIF for the establishment of a regional human rights mechanism has received support from Pacific Island MPs, judges and magistrates, and by NGOs.

In October 2007, Pacific Island MPs ${ }^{22}$ met in Auckland for a consultation on human rights issues. ${ }^{23}$ At the meeting, they called for the establishment of a regional human rights body to help PIF member countries with their obligations under the Pacific Plan to ratify, report on and implement international human rights conventions. The call by MPs was followed by a similar call in December 2007 by Pacific island judicial officials. ${ }^{24}$ The latest call was made in February 2008 by NGO representatives. Pacific MPs made specific mention of the following in calling for the setting up of a regional commission, namely that: ${ }^{25}$

This initiative should be driven by an indigenous regional human rights organisation of Pacific Islanders. This is critical for ownership by PIC Governments and peoples because of the perception that human rights are alien to Pacific societies.

20 Ibid, 15.

21 Ibid, 6 (emphasis added).

22 From the Cook Islands, Kiribati, Samoa, Federated States of Micronesia, Nauru, Niue, Papua New Guinea, Solomon Islands, Tuvalu and Vanuatu.

23 The Consultation was organised by RRRT with support from the Forum Secretariat, the Commonwealth Secretariat and the UNDP - Pacific Centre and was held in Auckland. In most cases both opposition and Government parties from each country were represented at the meeting.

24 From the Cook Islands, Tonga, Vanuatu, Samoa, Kiribati, Fiji, Solomon Islands and Tuvalu.

25 The NGO representatives were part of a meeting organised by RRRT for its partner organisations in the Pacific region to discuss, amongst other things, the advocacy plans of these organisations in their countries in the next five years from the Cook Islands, Fiji, Kiribati, Samoa, Solomon Islands, Tuvalu, and Vanuatu. 


\section{B A Regional Mechanism will Help Foster a Pacific Human Rights Culture}

A regional commission will facilitate and foster an appreciation of human rights values within the citizenry of PICTs, in both government and civil society. It will create the necessary environment for the dialogue of international human rights and Pacific culture and help create a widespread body of human rights case law specific to PICTs.

\section{The Pacific will Soon be the Only Region without a Regional Mechanism}

In November 2007, ten Asian member countries of the Association of Southeast Asian Nations (ASEAN) signed a charter moving a step closer to committing to promote human rights and democracy. ${ }^{26}$ One of the significant pledges in the Charter is the setting up of a regional human rights body. ${ }^{27}$ If these countries succeed in establishing a regional human rights body of their own, the Pacific region will be the only region in the world without such a commission.

The working group for an ASEAN human rights regional mechanism states that the benefits of such a mechanism are that it can: ${ }^{28}$

(1) Assist ASEAN member states in addressing human rights concerns in their respective areas of jurisdiction;

(2) Ensure that international human rights laws are observed and implemented by ASEAN countries who have agreed to them; and

(3) Help ASEAN peoples have a common understanding of universal human rights issues and perspectives.

These reasons apply equally to the Pacific region. For Pacific Governments that are members of the $\mathrm{UN},{ }^{29}$ this should be a matter of concern, as it constitutes non-compliance with the many resolutions of the UN that call for the setting up of such an institution. From 1986 - 1990 the UN General Assembly had passed three such resolutions. For example, Resolution 41/153 passed in 1986 and titled "Regional Arrangements for the Promotion and Protection of Human Rights in the Asian and Pacific Region" called upon states from the region to respond to the call for "regional arrangements". The UN Human Rights Council (previously Commission) had also made nine similar calls. ${ }^{30}$ The lack of response to the calls by UN members in the Pacific region will certainly

26 Association of Southeast Nations (ASEAN) Charter (20 November 2007) www.aseansec.org/ASEANCharter.pdf.

27 http://news.bbc.co.uk/1/hi/world/asia-pacific/7102992.sm (accessed 10 March 2007).

28 www.aseanhrmech.org (accessed 18 April 2008).

29 All Pacific Islands Forum countries except Cook Islands and Niue are members of the United Nations.

30 Muntarbhorn, above n 8. 
raise questions about their commitment, as members of the international community, to their international obligations.

Of course the fact that we would be the only region in the world without a regional human rights commission is hardly justification in itself. However all PICTs are signatory to at least one human rights convention. This in itself reveals a desire to increase capacity for the further development of human rights.

\section{The Challenges of Complying with the Paris Principles}

At a 1991 UN-sponsored meeting of representatives of national institutions held in Paris, a detailed set of principles on the status of national institutions was developed - these are commonly known as the "Paris Principles". ${ }^{31}$ These principles, subsequently endorsed by the UN General Assembly, ${ }^{32}$ have become the foundation and reference point for the establishment and operation of national human rights institutions.

If PICTs do establish a national commission they need to comply with the minimum standards set out in the Paris Principles. In summary the key criteria of the Paris Principles are: ${ }^{33}$

(1) Independence guaranteed by statute or constitution;

(2) Autonomy from government;

(3) Pluralism, including in membership;

(4) A broad mandate based on universal human rights standards;

(5) Adequate powers of investigation; and

(6) Sufficient resources.

These are important criteria and are the benchmark for standards. RRRT emphasises these criteria to MPs, judicial officials, decision makers, lawyers, law students and NGOs consistently during our training and mentoring of champions. However the challenges of compliance with the Paris Principles for all our PICTs, let alone the smaller island states are manifold. How do countries like Tuvalu (population 9561), ${ }^{34}$ Tokelau (population 1466), ${ }^{35}$ Niue (population 1679), ${ }^{36}$ Cook

31 Principles Relating to the Status and Functioning of National Institutions for the Protection and Promotion of Human Rights UNGA Res 48/134 (20 December 1993) [hereafter Paris Principles].

32 United Nations Resolution 48/134 (20 December 1993).

33 Paris Principles (20 December 1993) UN Doc A/RES/48/134.

34 See pacific.unfpa.org/Countries/tv.htm.

35 See www.mfat.govt.nz/Countries/Pacific/Tokelau.php.

36 See www.helproot.com/. 
Islands (population 11,900$)^{37}$ or even Tonga (population 97,784$)^{38}$ fully comply with such minimum standards on a national basis?

The problem of resource constraints faced by most Pacific island countries will mean that the Paris Principles relating to the status of national human rights institutions will be hard to meet for many of them. One of the Principles requires national institutions to have adequate funding for staff and premises so that they are independent of Government control. In many PICTs even the radio, newspapers and TV stations are not free of Government influence, and in some, the only media is Government owned. How can a commission be independent without a strong and robust human rights culture to ensure its independence? The status enjoyed by the military with the national commission in one PICT country is an open secret providing a salutary reminder of the difficulties of always implementing the Paris Principles. The publication by the PIF Secretariat and the New Zealand Human Rights Commission, Pacific Pathways, recognises these difficulties and acknowledges that PICTs may need to give their "own unique expression to the international standards (the Paris Principles) for NHRIs". ${ }^{39}$

It is all very well to sit in offices in Sydney, Auckland, Geneva or even Suva and demand that PICTs comply fully with the Paris Principles but those who make these demands have no understanding of the everyday realities of life in PICTs. Not all Pacific countries will be able to satisfy these criteria. A regional commission on the other hand may better satisfy the Paris Principles for PICTs.

\section{E A Regional Commission will have Greater Independence}

In countries such as Fiji, which has its own national human rights body, the additional advantage of a regional body is that it may provide redress where the national system is unable to deliver justice. A regional commission will also better ensure that no individual country will be able to assert control or influence on its work. As a regional body, with its own charter and rules, it will be more difficult for an individual country to influence or interfere with its work. Recent criticism of the Fiji Human Rights Commission for its stand on human rights abuses by the interim regime is an example of the vulnerability of national institutions to political influence in small countries. A regional human rights body appropriately staffed and mandated is in a better position to operate with a greater degree of independence than its national counterpart.

Another appeal of a regional human rights body in the Pacific context is that it will be better able to insulate itself from problems of cronyism, "wantokism" and nepotism. This may be a

37 See www.stats.gov.ck/ (accessed 1 June 2008).

38 See www.southpacificrealestate.com/ (accessed 1 June 2008).

39 PIF Secretariat and New Zealand Human Rights Commission (2007) "National Human Rights Institutions Pathways for Pacific States, Pacific Human Rights Issues" 1. 
problem with national institutions, especially in small countries, where close relationships are important and where professionalism, transparency and ethics are often sacrificed in order to keep relationships intact. A common challenge faced by public officers who deal with complaints and investigations, is not being able to deal with their relatives or friends because of their relationships, or of aggrieved persons not taking up their grievances to appropriate authorities because of their lack of trust in them. There have also been cases of persons pressured not to report on leaders because of their connections. A regional body will enhance the possibility of arms-length decisionmaking. It will be better able to maintain the trust and confidence of the people to deal with complaints independently, and thus empower people to take their grievances directly to it.

\section{F The Rule of Law Challenges Faced by Nascent Democracies in the Pacific}

There are many rule of law challenges faced by national bodies in small countries. They are vulnerable to interference from Government, militaries and potentially, police forces as well. I would suggest that having a regional commission makes such problems less likely to happen and less vulnerable to national political interference.

\section{G To Enable Regional Co-operation and Realisation of the Pacific Plan and Provide a Critical Service to the Pacific Region}

The realisation of human rights is critical to the achievement of all fifteen Strategic Objectives in the Pacific Plan, but in particular to those of reduced poverty, improved health, improved education and training, improved gender equality, improved recognition and protection of culture, identities and traditional knowledge, improved transparency, accountability, equity and efficiency in the management and use of resources, improved political and social conditions for stability and safety, and increased national ownership and commitment to regional approaches, plans, policies and programmes. Virtually all of these objectives are also goals of human rights treaties. ${ }^{40} \mathrm{~A}$ regional human rights commission can play a crucial role in facilitating the realisation of the goals of the Pacific Plan.

The additional appeal of a regional human rights commission for the Pacific region is the fact that it will provide a service which is currently unavailable in most countries. At the present time, only Fiji has a human rights commission. With the exception of Papua New Guinea, the Solomon Islands and perhaps Samoa, the possibility of other countries being able to set up their own human rights bodies is remote given the size of their population and resource constraints.

An example of a service which is unavailable in most PICTs is support for the ratification, reporting and implementation of international human rights treaties. The Pacific Plan, as noted

40 P I Jalal "Pacific Culture and Human Rights: Why Pacific Island Countries Should Ratify International Human Rights Treaties" RRRT/UNDP (unpublished paper, 2006) 24 available at www.rrrt.org. 
earlier has highlighted this as an immediate need to be addressed. Overall, the Pacific region has the lowest rate of ratification globally. ${ }^{41}$

\section{H A Regional Commission can be Resourced by Pacific Island Specialists}

Most PICTs cannot afford specialised courts, commissioners and staff. Like a national human rights commission, a regional commission has the advantage of being resourced by specialists in human rights, including persons with experience in UN bodies and human rights mechanisms. It is critical that not only lawyers but also people from the NGO sector with a background in human rights are included as staff.

It is also crucial that a regional human rights commission is led and staffed by qualified Pacific people. This is fundamental to receiving the support and acceptance of the people that it will serve. The fact of the matter is that some degree of expertise now exists in the Pacific Islands. This ought not to be taken to mean that expatriate expertise is not needed to train and mentor those who resource the regional commission.

\section{Financial Constraints}

Many worthy initiatives in the Pacific fail for want of financial and human resources. Thus initiatives to set up national mechanisms fail due to a lack of resources, especially for small or resource-poor island nations. A regional mechanism however will allow PICTs to pool their resources.

The reality is that there are severe financial and human resource constraints on the ability of the Pacific countries to ratify and implement international human rights conventions. For example, all countries relied on donor support when they prepared their reports for CEDAW and the CRC. ${ }^{42}$ A regional body appropriately staffed could be tasked with this responsibility. The added value is that the experience gained in one country by the regional body in ratification, reporting or implementation of international human rights treaties, could be used in other countries, thus avoiding duplication.

41 Of the main human rights conventions, only the Convention on the Rights of the Child (20 November 1989) 1577 UNTS 3 has been ratified by all the Pacific island countries. For CEDAW, above n 1, all except three countries have ratified; these are Nauru, Palau and Tonga. The International Convention on the Elimination of all Forms of Racial Discrimination (4 January 1969) 660 UNTS 195 has been ratified by four countries: Fiji, PNG, Solomon Islands and Tonga. Samoa has acceded the ICCPR, above n 2, whilst Vanuatu has ratified it. The Solomon Islands adhered by succession to ICESCR, above n 18, and Tonga and Vanuatu have signed the Convention on the Rights of Persons Living With Disabilities, above $\mathrm{n}$ 5. No country has ratified the Convention Against Torture and Other Cruel, Inhuman or Degrading Treatment or Punishment (10 December 1984) 1465 UNTS 85 or the Convention on the Rights of Migrant Workers and their Families (18 December 1990) 30 ILM 1517.

42 Ibid. See also Jalal, above n 40. 


\section{J A Regional Commission may Lead to More NHRIs Being Established}

Whether or not national human rights commissions or analogous institutions at the domestic level should precede the development of a regional human rights system is a matter that should be addressed using a case-by-case approach. Within the Inter-American Human Rights system, for instance, at the time of its inception, national human rights institutions in the Americas were virtually non-existent. Rather, they were established as a result of the repeated calls in this regard which came from the Inter-American System as well as from UN bodies. Now almost every member of the IACHR has a NHRI. ${ }^{43}$ To be sure, in order to achieve the maximum effectiveness in the protection of human rights, both a regional system and a national institution is needed. I would suggest that advancement in one area promotes advancement in the other.

\section{SOME CHALLENGES AND STRATEGIES}

The renewed enthusiasm towards the establishment of a regional human rights commission for the Pacific region should not be left to wane. It calls for PICT governments, academics, activists, NGOs, development partners and international agencies to create a unified and powerful lobby to make this happen. A working group such as that set up by the ASEAN nations might be considered.

The most practical challenge that will have to be addressed is funding. A regional body will be easier to maintain, and it is in the economic interest of PICTs to support such a body. This will encourage countries to contribute to the operational costs. A funding model to be considered might be the arrangement adopted by existing regional institutions such as the University of the South Pacific.

The role of development partners, donors and international agencies in this area is also vital. Given the financial constraints faced by most Pacific island countries, they will be called upon to contribute to some of the costs at the initial stages. Needless to say, the success or failure of a Pacific regional body will depend on their goodwill and understanding.

A Pacific Charter on Human Rights might also provide for a regional human rights commission to be based initially within the PIF Secretariat or the Secretariat of the Pacific Community. The significance of it being seen as a regional Pacific body serving all PICTs cannot be overstated.

The regional human rights commission might be given powers to issue advisory opinions, promote human rights, receive complaints and hear and adjudicate disputes. In addition, they might also be tasked to assist in the ratification, reporting and implementation of human rights treaties. However, not all these mandates need be granted initially or all at once. The process could be a continuous one developing progressively over time. For example, although not my personal preference, a regional commission could start off with a simple mandate to promote human rights

43 The remarks made about the Inter-American system were made by Felipe González "The Experience of the Inter-American Human Rights System" in this volume. 
and gradually take on more complex remedies to conciliate, issue advisory opinions, adjudicate and so on. Any charter should also take into account the mechanisms available in member countries and ensure that its constituent regional body recognises and complements their roles.

There is already in existence a Draft Pacific Charter of Human Rights, prepared under the auspices of LAWASIA and other parties. ${ }^{44}$ Although it may require review, this should be less tedious and time consuming than starting afresh. We also have many models from other regions to assist us. Moreover, all stakeholders in the region, including NGOs, national human right institutions, ombudsman offices, businesses and regional institutions should be given the opportunity to contribute their views.

\section{CONCLUSIONS}

Despite the protection provided by national constitutions and international human rights law, violations of people's rights continue to occur in the Pacific. Poverty is on the increase and access to essential services is still an issue. The Pacific Plan appropriately addresses these, but it cannot bring about change without action and an enforcement mechanism provided by the treaty reporting process.

The lack of protection at the national level, and the incapacity to provide redress justify a regional commission that should be appropriately structured, staffed and mandated to deal with these issues. The threat of scrutiny by the regional body, let alone scrutiny of its reports by other member states, as is the experience with other regional bodies, might persuade countries to pay closer attention to these violations.

In a nutshell, a regional human rights body for the Pacific region will not only facilitate the realisation of the fifteen Objectives of the Pacific Plan, but will also fulfil the mandate of the Forum leaders in terms of facilitating ratification and implementation of international human rights treaties. It will also afford more protection and safeguard to the rights of the Pacific people enshrined in their constitutions and in various international human rights instruments.

The establishment of a human rights regional mechanism within the Pacific Plan framework still requires more debate and political consensus on its possible form, functions and mandate. However a viable overall option could be a comprehensive regional commission with the responsibility to promote and defend human rights and to provide technical and financial support for ratification, reporting and implementation. This could be a broad-mandated regional human rights commission.

44 See "Report on a proposed Pacific Charter of Human Rights prepared under the auspices of LAWASIA May 1989" (1992) 22 VUWLR Monograph 4 referred to in C Wickliffe "Human Rights Education in the Pacific" Paper for UNESCO Asia/Pacific Meeting on Human Rights Education (India, 1999) available at www.vanuatu.usp.ac.fj/journal_splaw/Working_Papers/Wickliffe1.htm (accessed 18 January 2008). 
A charter and regional human rights mechanism must be an initiative of the Pacific peoples as a whole. It must truly represent and consider all views of its constituents. The greatest challenge lies in the formulation of this body. However these difficulties are not insurmountable; our leaders, officials, and NGOs have spoken. The commitment and participation of member Governments, their people, institutions, and NGOs as well as regional bodies, are of the utmost importance. Likewise is the goodwill and support of development partners and international agencies. 